\title{
ANALYSIS OF THE RESULTS OF AUDITS OF QUALITY MANAGEMENT SYSTEM-SALES SERVICE OF CARS
}

\author{
JAROSLAV JAMBOR
}

\section{INTRODUCTION}

One of the management strategies for business success in the market is a strategy of continuous improvement of production quality through the implementation of quality management and continuous improvement. Improving product quality then affects not only the production processes, but also post-production activities such as selling and servicing vehicles. The new EU regulation on the common exemptions (BER Block Exemption Regulation, Chapter 2.4.1) and strategic considerations developed in the company SEAT has resulted in the implementation of new quality management system on the market service (after sales) services (ServiceQualityManagementSystem SEAT, SSQMS). In this system, were also included qualitative criteria for partners in SEAT-sales business. In practice this means that these quality criteria are required to comply with all authorized service providers SEAT. These criteria are also minimum standards to be met by any new candidate (applicant is a contract service partner SEAT) having the objective of integration into a network of authorized partners SEAT. This system was put into operation in May 2004 for the Slovak Republic and Czech Republic. The quality criteria defined in the SSQMS include requirements for two areas:

- Service Standards and Norms for SEAT Genuine Parts SEAT

- Criteria for ISO 9001

To measure the efficiency and effectiveness of the implemented quality management system called SSQMS were between 2004 and 2008 successfully used third-party audits (external audits SSQMS) through certification company TÜV SÜD Automotive GmbH, Munich. This paper is the desirability of introducing quality management system. This is documented in the analysis and results for a particular sample car dealer network SEAT brand for four years of the existence of the system. 


\section{CONDUCT AUDITS SSQMS}

Implementation of standards is verified annually SSQMS audit. To standardize SSQMS audits and to ensure objectivity and unlimited non-discriminatory treatment of all partners SEAT (and all applicants for contract service partner SEAT), the manufacturer decided to leave the implementation of audit procedures independent service provider. Selected the company TÜV SÜD Automotive $\mathrm{GmbH}$, Munich. The audit carried out by three auditors for the Slovak Republic and the Czech Republic. The advantage was that it came from Slovakia, and audits are carried out in Slovak or Czech language. It was dismantled language barrier between the auditors and verification service partners SEAT. Previously, auditors passed the selection procedure in order to represent the company TÜV SÜD Automotive GmbH, Munich. Training course for auditors SSQMS standards and testing took place in the English language in two phases. Initial training was carried out in IVG Praha s.r.o. and other training took place in the parent company in Germany.

Audit activities and the sequence of steps was carried out in accordance with ISO 19011:2002. After a successful audit has been certified service partner of the QMS (Quality Management System) and ISO 9001:2000 certificate as required by the manufacturer, so. SSQMS certificate. SSQMS main tool was a checklist of questions. This list contained all the standards for service partner SEAT and work to simplify these standards as defined by issues.

The checklist is divided into individual processes that are defined for an authorized service center SEAT and is divided into the following five areas:

1) Buildings

2) Management, processes, organization and personnel

3) Contact place of customers

4) Spare parts

5) Workshop

This division greatly facilitate the work of service, particularly in introducing SSQMS in practice and in defining the various remedial measures in improving quality. A checklist of questions is also a self-assessment tool for our service partners, as it will allow any time to check compliance with the requirements of quality management system. SSQMS system but serves only to check compliance with prescribed standards, which are given by the manufacturer. It is intended to improve the quality of service provision and therefore are also part SSQMS Phantom test (quality), which are carried out in individual service partners. As mentioned above from the view of these tests are performed by an independent service provider - TÜV SÜD Automotive GmbH. It also contains a checklist of criteria (questions) are not defined as a manufacturer of quality (standards), ie. that service partner in the audit does not meet these criteria. These criteria call or optional recommended. Failure criteria, optional service partner partiall lost competitive advantage in servicing the market (Handbook Service 
Organization, 2003). SSQMS main tool is a checklist of questions. This list contained all the standards for service partner for SEAT and simplification of work are defined by standards issues. This checklist is based on individual processes is called the check list. The entire certification process is included in the three-year cycle, see figure. 1 st:

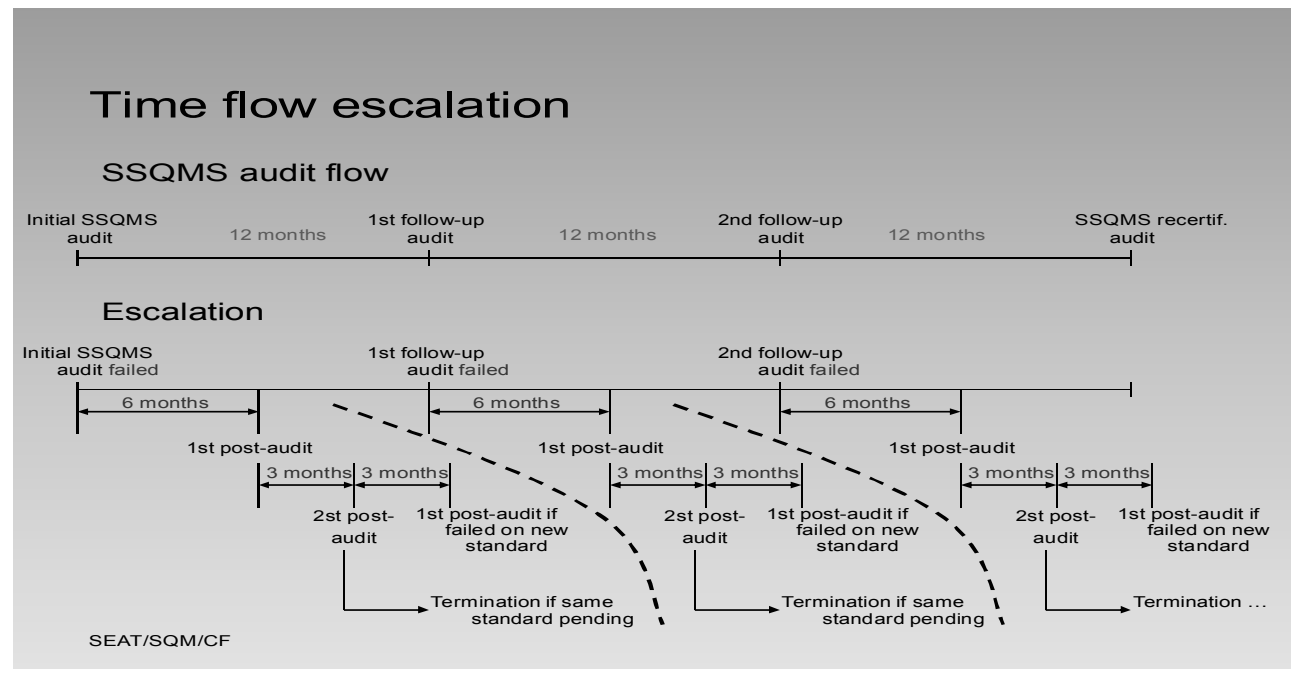

Figure 1 - Three-year audit cycle SSQMS

As shown in Figure No. 1 audits are divided into two types: Certification Audit and Audit Control.

At the beginning of the cycle is performed the certification audit, whose validity is one year. Within one year ( $+/-9$ weeks) must be executed first control audit, whose validity is again one year. In the next year following the first surveillance audit (+/- 9 weeks) must be conducted the second inspection audit. After this second inspection audit is not yet determined the validity of the audit for one year and the year cycle is closed. After this three-year cycle must be carried out and the new certification audit, the new three-year cycle. In the event of failure of the audit or certification or inspection, the dealer has to make within three months of remedial audit - postaudit. If at this postaudite failed and could not fulfill the conditions of certification, getting one more chance and the next three months must be made postaudit second. In case of failure of the second postaudit is terminated with the dealer service contract and cease to be authorized service SEAT. If you wanted to reconnect to a three-year certification cycle must have a compulsory two-year break. After this period may again register as a new applicant for a contract service partner SEAT. However, if the trader is successful if the first or second postaudit, not shift the date of the next audit review to date from last year postaudit. The term audit is set every year postaudit not affect the deadline. Of course, all audit and financial postaudit is charged and the retailer is also in this form SSQMS motivated to meet the criteria for the first time. Just for illustration is a brief description of the financing described SSQMS 
audits of the service partner respectively (Internal materials of SEAT dealer, 2004).

\section{SSQMS cost of the audits and the certification process.}

Auditee pay a specific price for a three-year audit period in the company TÜV SÜD Automotive GmbH. The resulting amount is divided into three partial payments. The advantage is that the service is charged at the same time a great partner funding, but the payment is divided into three installments, with no increase.

Price for the audit includes the cost of an audit, the costs associated with the release of ISO 9001:2000 certificate issued by TUV Management Service GmbH and the cost of the certificate SSQMS.

In case of failure to audit the auditor decides whether to take postaudit spot with a service partner, or only made known paper audit of the office. Postaudit spot is always performed if it is a fundamental disagreement on the so-called failure. KO criteria listed in the check register. Paper audit carried out by the auditor only if the failure criteria are not radically so that it sends a specific service partner materials by mail in paper form for subsequent evaluation. Postaudit (amending audit) on the ground is costly because the price is about one third of the total amount for the audit for three years. Each paper is postaudit amount charged $600 €$.

Workshop equipment and service literature. For each service partner SEAT require workshop equipment, including special equipment, special tools and service literature. These obligations are included in SSQMS standards and are reviewed in the audit. The financial burden of this equipment is not a high amount (about $€ 3,400$ ).

Programs and Systems SEAT SA Importer and develop programs and systems for communication with service partners to support the SEAT of all business activities. These programs and systems require standardized data availability within a service organization SEAT. Therefore, participation in these programs and systems required for all service partners SEAT. SEAT Service Partner must ensure that information systems are compatible with the programs and systems used by SEAT. Certificate issued by SEAT or service provided by SEAT serve as evidence of the compatibility of information systems service partner SEAT. Also in this case is controlled by system software to connect to the audits SSQMS SEAT.

When all these criteria, the applicant becomes a dealer or an authorized service and SEAT SSQMS the Certificate issued by TÜV Management Service GmbH Munich (Handbook Service Organization, 2003). 


\section{PERFORMANCE EVALUATION AUDITS SSQMS}

The first positive results from the introduction of SSQMS service partners in the show after two years of operation. Significant improvement in the quality of sales-service posts were seen after four SSQMS existence, which was documented in the results of the evaluation of customer satisfaction CSS (Customer Satisfaction Survay) and the results of the evaluation of satisfaction dealers DSS (Dealer Satisfaction Survay). CSS and DSS are directly linked and related analysis of customer satisfaction and dealers, as if it is satisfied then the ultimate customer satisfaction and dealer of vehicles of a particular brand because it has provided increased sales of its products. The gradual improvement of customer satisfaction are documented after the third and fourth flow there SSQMS (introduced since 2004) in the following Table no. 1 with bar chart.

Table 1 - Slovakia, CSS SEAT, STAGE 2006, before the entire network and 2007, after the entire network

\begin{tabular}{|c|c|c|}
\hline Slovakia SEAT code & Year 2006 & Year 2007 \\
\hline SK005 & 88.6 & 56.0 \\
\hline SK008 & 83.1 & 89.3 \\
\hline SK036 & 61.4 & 55.8 \\
\hline SK037 & 76.1 & 83.7 \\
\hline SK038 & 90.0 & 81.0 \\
\hline SK040 & - & 89.3 \\
\hline SK042 & 86.1 & 82.9 \\
\hline SK043 & 64.3 & - \\
\hline SK044 & 86.2 & 100.0 \\
\hline SK046 & 81.0 & 71.8 \\
\hline SK047 & 92.9 & 96.4 \\
\hline SK048 & 73.3 & 100.0 \\
\hline SK049 & 94.8 & 102.5 \\
\hline SK051 & 74.2 & 83.2 \\
\hline SK052 & 82.7 & 79.1 \\
\hline SK054 & - & 89.8 \\
\hline SK055 & - & 77.5 \\
\hline SK056 & 71.0 & 62.0 \\
\hline SK057 & 69.5 & 81.4 \\
\hline SK059 & 76.4 & 93.5 \\
\hline SK060 & 91.9 & 76.8 \\
\hline SK064 & 71.0 & 89.3 \\
\hline SK066 & 90.3 & 79.4 \\
\hline SK067 & 75.8 & 57.1 \\
\hline SK069 & - & 80.0 \\
\hline
\end{tabular}




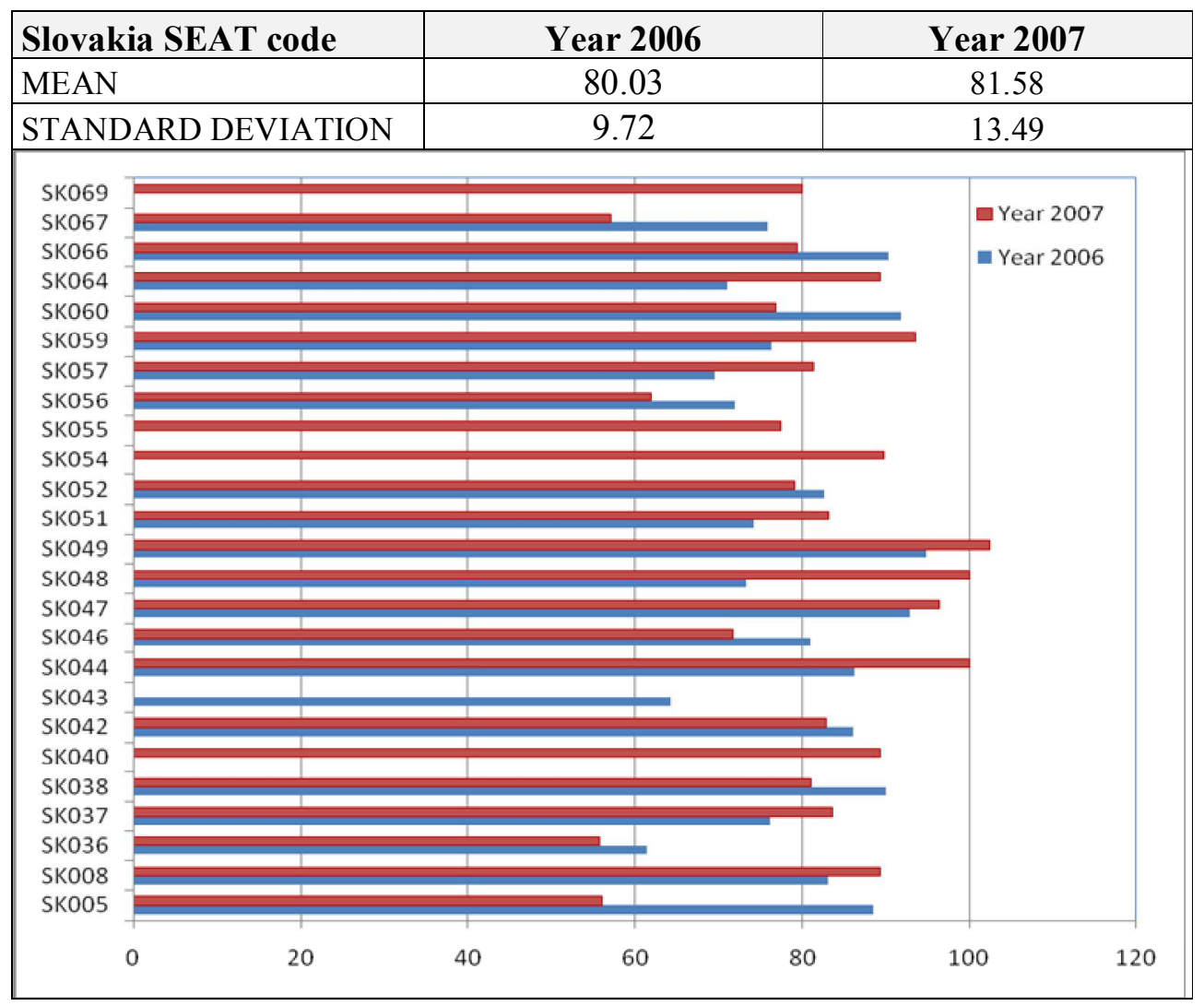

The results show that customer satisfaction grow in the last analyzed in 2007 (results have been comprehensively evaluated in 2008 for the previous year 2007) of 2.7 percent compared with 2006. Overall, the reference years 2004 to 2007 was to increase customer satisfaction by 12.8 percent, a substantial improvement in the quality of products. Those partners who introduced SSQMS not only because of concerns about the withdrawal of licenses for service activities, but also because of the streamlining and simplification activities in service and sales should increase profitability by an average of $3 \%$ to $10 \%$. Overall improvement of the system shown in particular:

- Reduction in customer complaints;

- Increase in the number of passage guides through service;

- Increase in the number of vehicle sales, or retaining the original volume of sales in the sharp increase in competition from other brands (Suzuki, Hyundai, Kia, etc.).

- Transparency of the accountability of staff engaged in various activities;

- The clarity of documentation and records the execution of all activities;

- Increase customer satisfaction and trust from customers. 
For those service partners, who have not been consistent in implementing SSQMS experienced the following shortcomings:

- Well-documented records of staff training;

- Differences in education planning staff to the standards and importer of SEAT;

- Lack of special tools, fixtures and equipment workshop;

- Not fully implemented activities related to convening and service actions;

- Lack of special preparation and calibration tools;

- Failure of telephone contacts with customers, following receipt of the vehicle from service, or just the formalization of this activity.

Some service partners have tried to introduce SSQMS only paper - certificate. They understand the system and there has been no improvement in them after four years. Losing customers and got into financial problems.

Service partners who have implemented SSQMS not only for its issue, but also to streamline, simplify and streamline the system had the advantage of maintaining the market share or market share, expansion of sales and service vehicles.

\section{CONCLUSION}

Based on the experience of the audit shows that the quality management system is beneficial only if:

a) practical - is tailor-made and suitable for business managers achieve the intended results (all activities are facilitated, all materials and information can be found immediately, each employee knows what to do, how to do, is set out clearly substitution and competencies ...)

b) economic - the ultimate aim of introducing a system of quality management and business is to achieve a positive profit (reduce costs, increase sales, increase profitability ...)

c) documented - is processed quality policy, quality objectives, quality manual, card processes, documented procedures, records (each action is recorded and described, signed by the responsible person making the actual performance ...)

d) continuous improvement - the improvement of all activities and everything in the company can improve the ever-changing needs and customer requirements (continuous collection of views of customers regarding their satisfaction and ideas for process improvement.)

If the management of service partners and sales for cars understand interconnection link above, then be motivated to implement quality management 
systems not only technically but also from the pragmatic. Finally, SSQMS that is practical, economical, documented, and constantly improving service brings many benefits to partners who can correctly understand and implement (Jambor, 2009).

\section{REFERENCES}

Handbook Service Organization (2003), Edition 03, SEAT S.A.: Ref. OSA248070.

JAMBOR, J. (2009), “Audit systému manažérstva kvality servisného a predajného miesta automobilov", in: Proceedings of the $18^{\text {th }}$ Internation Congference KVALITA-QUALITY'2009, 19.-20. May 2009, Ostrava: DTO CZ, s.r.o, ISBN 978-80-02-02153-7, pp. H24 - H28.

TÜV SÜD Automotive GmbH Internal materials (2004), TÜV SÜD Automotive $\mathrm{GmbH}$, Munich.

\section{ABOUT THE AUTHOR}

Ing. Jaroslav Jambor, PhD. - Alexander Dubcek University of Trencin, Department of Metrology and Quality Management, e-mail: jambor@tnuni.sk Specialization: Graduate of the Slovak University of Technology in Bratislava, focusing on economics and management of engineering production. He has rich experience in implementing and auditing quality management system. 